\title{
Understanding the effects of different parameters of Soxhlet extraction on bioactive compounds from Aquilaria malaccensis leaf through GCMS-based profiling
}

\author{
${ }^{1}$ Zainurin, N.A.A., ${ }^{2, *}$ Hashim, Y.Z.H-Y., ${ }^{1}$ Mohamed Azmin, N.F. and ${ }^{1}$ Al-Khatib, M.F.R. \\ ${ }^{1}$ Department of Biotechnology Engineering, Kulliyyah of Engineering, International Islamic University \\ Malaysia (IIUM), Jalan Gombak, 53100 Kuala Lumpur, Malaysia. \\ ${ }^{2}$ International Institute for Halal Research and Training (INHART), International Islamic University \\ Malaysia (IIUM), Jalan Gombak, 53100 Kuala Lumpur, Malaysia.
}

Article history:

Received: 14 August 2019

Received in revised form: 25

September 2019

Accepted: 26 September

2019

Available Online: 10

February 2020

\section{Keywords:}

Agarwood,

Aquilaria malaccensis,

Bioactive compounds,

Gas chromatography-mass

spectrometry,

Principal component analysis

DOI:

https://doi.org/10.26656/fr.2017.4(S1).S09

\begin{abstract}
Bioactive compounds from plants have been shown to possess therapeutic values which are being used as medicine as well as ingredients for functional foods and nutraceuticals. While qualitative and quantitative studies on the bioactive compounds of plant extract are important to establish their claimed therapeutic properties; less is focused on effects and interrelationship of process (extraction) conditions used to obtain the desired bioactive compounds. As such, this study intended to determine the effects of different parameters on the extraction of Aquilaria malaccensis leaf extract (ALEX) bioactive compounds. Metabolite profiling of bioactive compounds of ALEX samples was conducted using gas chromatography-mass spectrometry (GCMS) with subsequent multivariate statistical analysis through principal component analysis (PCA) with the aid of MATLAB software. The GCMS analysis detected diverse potential bioactive compounds in ALEX samples with hydrocarbon, terpenes and esters being the primary groups. n-hexadecanoic acid and hexadecanoic acid, 2-hydroxy-1-(hydroxymethyl)ethyl ester were found to be present in most of the ALEX samples. PCA showed that same Soxhlet extraction parameters were able to cluster the samples together and separate samples extracted with different extraction parameters based on the relative abundance of the particular compounds. In conclusion, it is notable that the samples were significantly separated based on Soxhlet extraction time as compared to the solid to solvent ratio and the suggested best Soxhlet extraction parameters were $18 \mathrm{hrs}$ and 1:70 solid to solvent ratio. The findings from this study will facilitate the extraction and purification of the desired bioactive compounds from agarwood leaf that can be further used in development of functional foods and nutraceuticals.
\end{abstract}

\section{Introduction}

Bioactive compounds of natural products can be obtained from four main sources including plants, animal, microorganisms and marine organisms. The plant kingdom itself comprises of 300,000 to 400,000 species. According to Mushtaq et al. (2018), World Health Organization (WHO) stated that $80 \%$ of the world's population is depending on plant-based drug template for primary health care.

Aquilaria species is very well-known for its aromatic resin-containing heartwood which is called agarwood. Technically, the term 'agarwood' refers to the secondary metabolites which naturally forms due to the microbial infection or the defense mechanism against pathogens in wounded bark (Suhaila et al., 2015; Hashim et al., 2016). This infection could occur naturally (in wild trees) or through inoculation/injection of microbial concoction (in plantation). This non-timber forest product (agarwood infiltrated resin) has high demand and the prices can reach up to US\$100 000 per kilogram for superior quality (Jong et al., 2014). The agarwood infiltrated resin has been utilized for myriad types of applications mainly as folk medicine, perfume and incense (Hashim et al., 2016; Wang et al., 2018). For centuries, the incense has been widely used in Islamic, Buddhist and Hindu ceremonies (Wang et al., 2018). Meanwhile, the use of agarwood as a medicinal product has been recorded in the Sahih Muslim and in the Ayurvedic medicinal text the Susruta Samhita (Akter et al., 2013). Some of the 
potential pharmacological activities of Aquilaria species exhibited from various parts of infected and un-infected trees include anticancer, anti-inflammatory, antioxidant, antimicrobial, antidiabetic and antiallergic (Jok et al., 2015; Hashim et al., 2016). Consequently, the presence of promising bioactive compounds in Aquilaria species elucidates its potential health effects (Khalil et al., 2013; Hashim et al., 2016).

Based on Wang et al. (2018), there are thirty-one species of Aquilaria which can be found worldwide including in Malaysia, Indonesia, Thailand, China and India; and A. malaccensis is one of the major producers of the agarwood infiltrated resin (obtained from infected trees) and as such has received a lot of attention from the research community and traders alike. However, work on un-infected trees of this species are scarce let alone those focusing on leaf despite its abundance of supply. $A$. malaccensis leaf generally has a length of 5 to $11 \mathrm{~cm}$ and diameter of 2 to $4 \mathrm{~cm}$ with an elliptical blades shape (Hashim and Zuhaidi, 2011; Khalil et al., 2013). According to Khalil et al. (2013), alkaloids, flavonoids, saponins, terpenoids and tannins are present in leaves of non-inoculated and inoculated $A$. malaccensis trees. This could be exploited for development of therapeutic agents (Khalil et al., 2013). In Malaysia, the decoction of $A$. malaccensis leaf is applied externally to treat swelling and consumed to treat vomiting (Ibrahim, 2016). Meanwhile, tea derived from Aquilaria leaves is the most popular agarwood leaf-based product in the market. On the other hand, Adam et al. (2017) stated that the scientific report assessing the toxicological safety of agarwood tea sold in the markets in Hainan, China was first recorded in 2007. The tea, in the form of herbal infusion does not contain any caffeine and has been reported to cure insomnia (Kakino et al., 2010). Moreover, Ibrahim (2016) stated that the herbal tea of $A$. malaccensis, A. crassna and $A$. sinensis are found to have anti-depressant and anti-aging properties.

GCMS analyses detected 48 compounds in $A$. sinensis, A. malaccensis and A. crassna leaves methanolic extract with n-Hexadecanoic acid, squalene and phytol found to be present in these three species (Adam et al., 2018). The study also presented that only the methanolic extract of $A$. malaccensis had the cytotoxic effect with $\mathrm{IC}_{50}$ of $24.5 \mathrm{mg} / \mathrm{ml}$ and $\mathrm{LD}_{50}$ of $4537 \mathrm{mg} / \mathrm{kg}$; classified in Class III which is slightly hazardous. Nevertheless, it is notable that, according to US Food and Drug Administration (FDA), methanol is included in Class 2 solvents which are allowed to be used in specific cases with residual allowance of 50 to 3880 ppm (Rostagno and Prado, 2013). On the other hand, Maharani et al. (2016) reported that 3-Buten-one, 4-(-furanyl)- (28.88\%) and 3-Methylpyridazine (31.47\%) were found to be the major compounds of young and matured Borneo agarwood (A. malaccensis Lamk) leaves. Additionally, 3-Methylpyridazine, a nitrogen compound is widely used in pharmaceutical and agricultural industries, in which the compound was observed to be a potential precursor to agrochemicals and antidotes for organophosphate poisoning (Maharani et al., 2016).

Metabolites analysis of bioactive compounds from plant materials is generally influenced by the selection of extraction method and its parameters (Azmir et al., 2013). Accordingly, the pre-extraction and the extraction procedures are important preliminary steps in the processing of the bioactive compounds from plant materials (Azwanida, 2015). At present, studies related to agarwood that involved extraction, mainly focused on enhancing the yield and investigating the biological properties of the extract without justifying extraction parameters that affect the type and amount of bioactive compounds obtained. Thus, the present study intended to determine the most suitable parameters which may facilitate the effective extraction of desired bioactive compounds that can be used as halal ingredients including in the development of functional foods and nutraceuticals.

\section{Materials and methods}

\subsection{Raw material}

Samples of ALEX $(n=39)$ were obtained from an optimization study comprising of 13 experimental runs (triplicates) (Zainurin, 2019). The leaves of noninoculated Aquilaria malaccensis (agarwood plant which is not being induced or injected with microbial concoction for development of resin) were previously harvested from local agarwood farm in Sungai Kembong Hilir, Semenyih, Selangor, Malaysia. The leaves were authenticated by Herbarium of Kulliyyah of Architecture and Environmental Design, International Islamic University Malaysia (KAEDIIUM), which the voucher specimens were deposited with the number \#HBL707 [VS-1] (Zainurin, 2019).

\subsection{Chemicals and reagents}

Analytical grade reagents and solvents used in this experiment were purchased from Sigma-Aldrich Chemicals (St. Louis, MO, USA) and Merck Chemicals (Darmstadt, FR Germany) of analytical grade (purity > 99\%) unless otherwise stated.

\subsection{Method of extraction}

Soxhlet method was performed to extract 6 grams of A. malaccensis leaf in powdered form with a particle size 
Table 1. Analytical conditions for GCMS analysis based on the modification of method by Hashim et al. (2014)

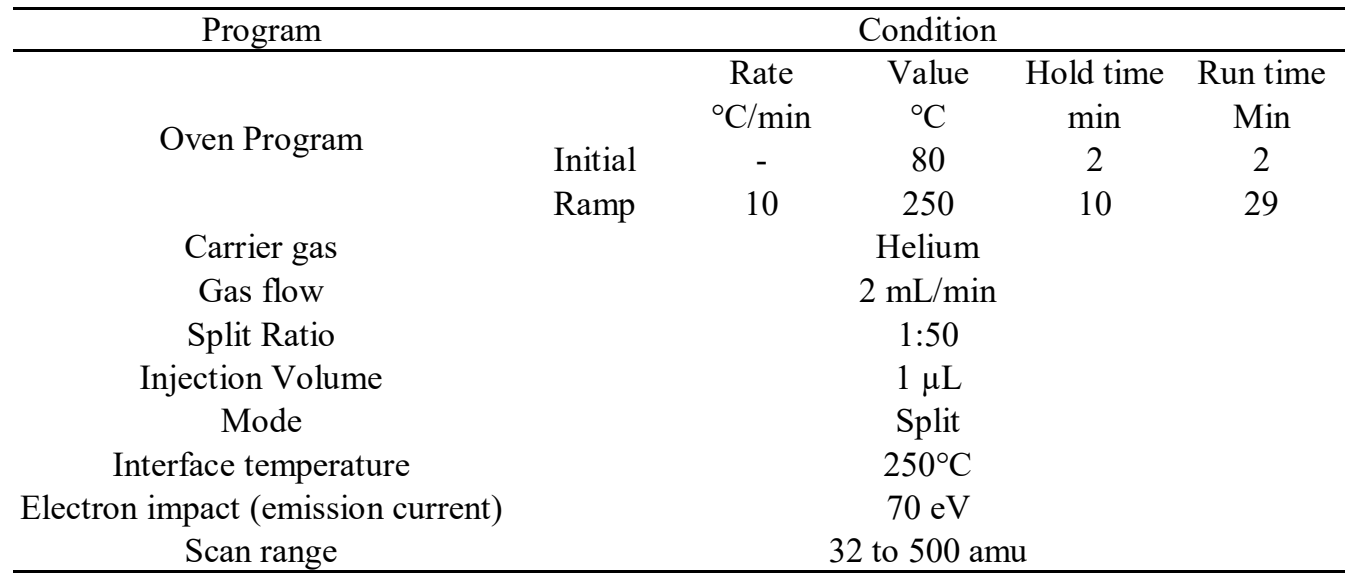

of $0.2 \mathrm{~mm}$. The samples were extracted at different Soxhlet extraction times of 12,15 and $18 \mathrm{hrs}$ and solid to solvent ratios of 1:50, 1:60 and 1:70 with absolute ethanol as the solvent extraction. The extract and excess solvent were evaporated under reduced pressure at $40^{\circ} \mathrm{C}$ using a rotary evaporator (Heidolph-instruments, Rotavapor, Germany) to give concentrated crude ethanolic extracts. The weight of the extracts was measured after solvent evaporation and then kept in the petri dish sealed with aluminium foil for further analysis (Ahmad et al., 2010; Lee et al., 2016; Ciarlini et al., 2017). A total of 13 experimental runs (triplicates; $n=39$ ) based on response surface central composite design (CCD) were generated using Design Expert Software.

\subsection{Gas chromatography-mass spectrometry}

The procedures for sample preparation and gas chromatography-mass spectrometry (GCMS) were based on Casuga et al. (2016) and Hashim et al. (2014) with modifications. ALEX with a concentration of $1 \%(\mathrm{w} / \mathrm{v})$ was diluted with respective solvent before being added into $2 \mathrm{~mL}$ microcentrifuge tube by using $20 \mathrm{~mL}$ pipette. The mixture was stirred well and filtered before being transferred into prepared GCMS vial. Samples were prepared in triplicates. The volatile constituents of ALEX samples were analysed using gas chromatography system; Agilent 7890A (Agilent Technologies) coupled with Agilent 5975C quadrupole mass spectrometer and autosampler. Hewlett Packard HP-5MS ultra inert silica capillary column ( $30 \mathrm{~m} \times 0.25 \mathrm{~mm} ; 0.25 \mu \mathrm{m})$ was used. The analytical conditions for GCMS are listed in Table 1. Identification of compounds was based on the detected peaks in the total ion chromatography (TIC) and mass chromatograms in accordance with the National Institute of Standards and Technology (NIST) 2008 mass spectral library.

\subsection{Principal component analysis}

The data sets of GCMS-based bioactive compounds from ALEX based on the retention time and relative abundance (total percentage of area content) were exported to the MATLAB software version R2016a for subsequent principal component analysis (Ali et al., 2012; Ballabio, 2015). Based on the scree, score and loading plots displayed, the number of principal components (PC) to retain was decided, the separation of ALEX samples based on extraction parameters and the correlation between the samples and specific bioactive compounds were observed respectively (Ballabio, 2015).

\section{Results and discussion}

\subsection{Gas chromatography-mass spectrometry analysis}

GCMS analysis revealed that the 39 ( 13 x triplicates) extracts of $A$. malaccensis leaf based on 13 experimental runs of response surface methodology (RSM), central composite design (CCD) gave a total of 555 bioactive compounds within retention times (RT) of 4.172 to 28.938 minutes. However, there were only a total of 45 compounds with mass spectral matching of more than $50 \%$ (Qual > 50) with the registered compounds in NIST mass spectral library detected within the retention times of 11.966 to 23.415 mins.

The compounds detected at the significant peaks of ALEX samples from the experimental design of the optimization study; Run 5 (highest yield of ALEX extracted for 18 hrs with ratio of 1:70) and Run 12 (lowest yield of ALEX extracted for $12 \mathrm{hrs}$ and ratio of $1: 70)$ at the retention times of 15.47 and 22.71 mins are listed in Table 2.

Table 2. The bioactive compounds detected at the significant peaks of the exemplary chromatograms of ALEX samples from the experimental design of optimization study; Run 5 and Run 12.

\begin{tabular}{|c|c|c|}
\hline \multirow{3}{*}{$\begin{array}{l}\text { Retention time, } \\
\text { RT (mins) }\end{array}$} & \multicolumn{2}{|c|}{ Bioactive compounds of ALEX samples } \\
\hline & Run 5 & Run 12 \\
\hline & (highest yield) & (lowest yield) \\
\hline 15.47 & $\begin{array}{c}\text { 1,19-Eicosadiene } \\
(17.790 \%)\end{array}$ & $\begin{array}{c}\text { Phytol, acetate } \\
(26.876 \%)\end{array}$ \\
\hline 22.71 & $\begin{array}{l}\text { Hexadecanoic acid, } 2 \\
\text {-hydroxy-1- } \\
\text { (hydroxymethyl)ethyl } \\
\text { ester }(40.749 \%)\end{array}$ & $\begin{array}{l}\text { Glycerol 1-palmitate } \\
(6.754 \%)\end{array}$ \\
\hline
\end{tabular}



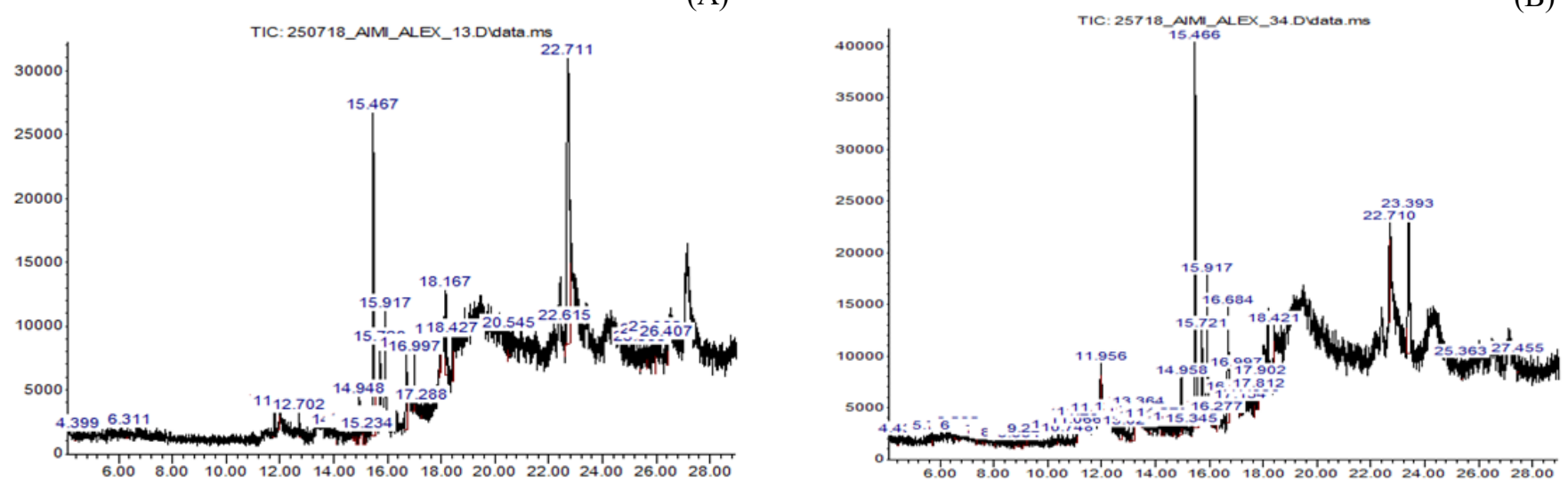

Figure 1. Exemplary chromatograms of ALEX samples from (a) Run 5 (highest yield) and (b) Run 12 (lowest yield); obtained using GCMS Agilent 7890A equipped with MSD quadrupole detector 5975 with capillary column HP-5MS

From Figure 1, which depicts the exemplary chromatograms of ALEX samples from (a) Run 5 and (b) Run 12, it can be observed that the trend of the chromatograms for ALEX samples of Run 5 and Run 12 are quite similar. Nevertheless, it can be spotted that ALEX sample of (a) Run 5 had two distinct peaks at RT 15.47 and 22.71 while ALEX samples of (b) Run 12 had three distinct peaks at RT: 15.47, 22.71 and 23.40. Hence, it showed that the sample extracted for shorter time produced more compounds with large area content $(\%)$, which suggested that more compounds were preserved from thermal degradation.

GCMS analysis of ALEX samples revealed that various functional groups with diverse bioactive compounds were detected from the extracts in which most of the detected compounds belonged to the class of hydrocarbon, terpenes and ester. Accordingly, nHexadecanoic acid and Hexadecanoic acid, 2-hydroxy-1(hydroxymethyl)ethyl ester were found to be present in most of the ALEX samples with content area of 3 to $12 \%$ and 14 to $35 \%$ of total ALEX content respectively.

n-Hexadecanoic acid has been previously reported in methanolic extracts of non-inoculated and inoculated $A$. malaccensis leaves at RT of 19.816 mins with total abundancy of $4.15 \%$ and $3.88 \%$ respectively (Khalil et al., 2013). Further, n-Hexadecanoic acid was the major compound constituted of $76.3 \%$ and $64.4 \%$ in the leaf essential oil of $A$. malaccensis and agarwood (the species was not specified) respectively (Lee et al., 2016; Zainurin et al., 2018) as well as in the agarwood oil from A. malaccensis wood (Sen et al., 2015). On the other hand, Eissa et al. (2018) reported that phytol was found to be the major compound which accounted for $34.1 \%$ and $29.3 \%$ in the hexane and ethanolic Soxhlet extracts of A. malaccensis leaves respectively at RT of 18.26 minutes. Conversely, phytol was detected in a much lower amount of 3 to $5 \%$ at RT 18.18 mins in the present study.
Interestingly, the identified bioactive compounds in ALEX samples possess various biological activities. In particular, hexadecanoic acid (synonym: palmitic acid), a saturated long-chain fatty acid with a 16-carbon backbone which is found naturally in fats and waxes was reported to have potential antioxidant, antitumor, antiinflammatory, antibacterial and antifungal activities (Aparna et al., 2012; Khalil et al., 2013). Meanwhile, previous studies showed that phytol which is acyclic diterpene alcohol has biological activities of antimicrobial, anticancer and anti-inflammatory (Maruthupandium and Mohan, 2011; Sermakkani and Thangapandian, 2012; Silva et al., 2014).

On the other hand, phthalic acid ester which was detected at RT 23.4 is a class of refractory organic plasticizer compounds that have been widely used in various products including medical devices, plastic film for food packaging and agricultural uses ( $\mathrm{He}$ et al., 2015). Despite of its promising biological properties discovered by Dr. Duke (U.S. Department of Agriculture, Agricultural Research Service) such as antidote (diaepam/digoxin), diuretic and coronary dilator, phthalic acid ester is also reported to be a potential contaminant in which the human exposure towards this compound could cause negative effects on the hepatic, reproductive and renal systems (He et al., 2015). Nevertheless, from Table 3, it can be seen that this compound was not detected when the sample was extracted for 18 hours.

D-erythro-Pentose, 2-deoxy-, n-Hexadecanoic acid, phytol and other compounds (Qual $>50$ ) of ALEX samples presented in Table 3 have been substantiated in Dr. Duke's Phytochemical and Ethnobotanical Databases (1992-2016), National Agricultural Library, created by Dr. Jim Duke of the Agricultural Research Service, United States Department of Agriculture (USDA), as the compounds that have anticancer property. Therefore, the putative biological activities of the listed compounds 
Table 3. Biological activities and ethnobotany uses of the bioactive compounds identified in the ALEX samples of Run 5 (highest yield; 18 hrs and 1:70 ratio) and Run 12 (lowest yield; 12 hours and 1:70 ratio) with mass spectral matching of more than 50\% (Qual > 50) with the registered compounds in NIST mass spectral library; NA: not available

\begin{tabular}{|c|c|c|c|c|c|c|c|}
\hline \multirow[b]{2}{*}{ No. } & \multirow[b]{2}{*}{ RT } & \multirow[b]{2}{*}{ Library/ID } & \multicolumn{3}{|c|}{ Average relative area content $(\%)$} & \multirow{2}{*}{ Biological activities* } & \multirow[b]{2}{*}{ Ethnobotany uses* } \\
\hline & & & Qual & $\begin{array}{c}\text { Run } 5 \\
\text { (Highest yield) }\end{array}$ & $\begin{array}{c}\text { Run } 12 \\
\text { (Lowest yield) }\end{array}$ & & \\
\hline 1 & 11.966 & $\begin{array}{l}\text { Methyl 4-O-acetyl-2,3,6- } \\
\text { tri-O-ethyl-.alpha.-d- } \\
\text { galactopyranoside }\end{array}$ & 50 & 0.937 & 1.652 & $\begin{array}{l}\text { Anticancer (oral) } \\
\text { Antitumor (ovary) }\end{array}$ & $\begin{array}{l}\text { Antidote (Opium/ } \\
\text { Wood oil) Obesity }\end{array}$ \\
\hline 2 & 14.132 & $\begin{array}{l}\text { Cyclohexan-1,4,5-triol-3- } \\
\text { one-1-carboxylic acid }\end{array}$ & 50 & 0.269 & 0.822 & $\begin{array}{l}\text { Acidifier, acidulant } \\
\text { arachidonic acid- } \\
\text { inhibitor, uric acid } \\
\text { production inhibitor }\end{array}$ & NA \\
\hline 3 & 14.958 & $\begin{array}{l}\text { 2- Chloropropionic acid, } \\
\text { hexadecyl ester }\end{array}$ & 55 & 0.966 & NA & $\begin{array}{l}\text { Acidifier, acidulant } \\
\text { arachidonic acid- } \\
\text { inhibitor, uric acid } \\
\text { production inhibitor }\end{array}$ & NA \\
\hline 4 & 15.467 & $\begin{array}{l}\text { Bicyclo[3.1.1]heptane, } \\
\text { 2,6,6-trimethyl- }\end{array}$ & 64 & NA & 7.906 & $\begin{array}{l}\text { Antifungal (Nikitina et } \\
\text { al., 2017) }\end{array}$ & NA \\
\hline 5 & 15.726 & $\begin{array}{l}\text { Dodeca-1,6-dien-12-ol, } \\
\text { 6,10-dimethyl- }\end{array}$ & 50 & 2.039 & NA & $\begin{array}{l}\text { Oligosaccharide } \\
\text { provider }\end{array}$ & Treatment for oliguria \\
\hline 6 & 15.91 & $\begin{array}{l}\text { 6-Octen-1-ol, 3,7- } \\
\text { dimethyl-, acetate }\end{array}$ & 64 & 2.371 & NA & $\begin{array}{l}\text { Oligosaccharide } \\
\text { provider }\end{array}$ & Treatment for oliguria \\
\hline 7 & 15.911 & Citronellyl isobutyrate & 72 & 2.74 & 1.371 & NA & $\begin{array}{l}\text { Food additives } \\
\text { (Flavouring agents) } \\
\text { (PubChem, 2018) }\end{array}$ \\
\hline 8 & 15.917 & $\begin{array}{l}3,7,11,15 \text {-Tetramethyl-2- } \\
\text { hexadecen-1-ol }\end{array}$ & 78 & 1.631 & 2.628 & $\begin{array}{l}\text { Oligosaccharide } \\
\text { provider }\end{array}$ & Treatment for oliguria \\
\hline 9 & 15.92 & $\begin{array}{l}\text { Cyclopentane, } 1,2- \\
\text { dimethyl-3-(1- } \\
\text { methylethenyl)- }\end{array}$ & 58 & NA & 2.841 & Endocrinprotective & $\begin{array}{l}\text { Treatment for } \\
\text { prophylaxis, enema, } \\
\text { enuresis }\end{array}$ \\
\hline 10 & 16.7 & n-Hexadecanoic acid & 96 & 4.617 & 10.189 & $\begin{array}{l}\text { Antioxidant, antitumor } \\
\text { (Nasopharynx), tumor } \\
\text { necrosis production } \\
\text { inhibitor factor }\end{array}$ & $\begin{array}{l}\text { Treatment for cancer, } \\
\text { nausea, nematicide }\end{array}$ \\
\hline 11 & 18.178 & Phytol & 53 & 1.049 & 3.152 & $\begin{array}{l}\text { Antimicrobial, anti- } \\
\text { inflammatory, diuretic, } \\
\text { anticancer }\end{array}$ & $\begin{array}{l}\text { Treatment for cancer } \\
\text { (rectum), fever } \\
\text { (remittent), preventive } \\
\text { (rheumatism) }\end{array}$ \\
\hline 12 & 22.7 & $\begin{array}{l}\text { Hexadecanoic acid, 2- } \\
\text { hydroxy-1- } \\
\text { (hydroxymethyl)ethyl } \\
\text { ester }\end{array}$ & 64 & 18.431 & 4.968 & $\begin{array}{l}\text { Antioxidant, } \\
\text { acidifier, acidulant, } \\
\text { arachidonic acid- } \\
\text { inhibitor, } \\
\text { uric acid production } \\
\text { inhibitor }\end{array}$ & NA \\
\hline
\end{tabular}

*Source: U.S. Department of Agriculture, Agricultural Research Service (2019).

may suggest that ALEX has the promising potential as the anticancer drug template as well as ingredients for the development of nutraceutical and functional foods. Meanwhile, the ethnobotany uses of the compounds may elucidate its traditional use and therapeutic relevance as the herbal medicine since past decades. Additionally, it is suggested that the samples extracted for 18 hours not only able to give higher yield but also constituted the non -toxic compound as compared to the samples extracted for 12 hours. Therefore, the discovery of these compounds may facilitate in establishing the most appropriate methods of extracting and purification of the desired compound. To this end metabolite profiling of ALEX offers the valuable insights to further explore its health benefits.

\subsection{Principal component analysis}

Multivariate techniques of pattern recognition such as principal component analysis (PCA), is a powerful tool for identifying the similarities and differences between clusters of complex samples (Kumar, 2017). In this work, multivariate data analysis techniques were used to study the effects of different parameters of extraction on ALEX. Based on GCMS analysis, the profile of bioactive compounds of ALEX samples obtained at different extraction times and solid to solvent ratios of Soxhlet process were different in terms of the total number and types of bioactive compounds as well as the relative percentage area (\%) of total ALEX content. There were a total of 45 compounds with mass spectral matching of more than 50\% (Qual > 50) with NIST 2008 mass spectral library detected in all $39(13 \mathrm{x}$ triplicates) extracts. 
PCA was applied in this study to reduce the dimensionality of a large number of interrelated variables and datasets, increase the interpretability as well as minimize the loss of information at the same time (Jolliffe and Cadima, 2016). PCA involved two types of data matrix; (a) $39 \times 555$ (dataset A) and (b) $39 \times 45$ (dataset B). The data matrix was assembled with each row corresponding to the observation (samples of ALEX) and each column representing the variables (relative percentage content area (\%) of detected bioactive compounds).

The result of PCA was illustrated through the graphical overview in three types of plot namely scree, score and loading, generated by MATLAB ${ }^{\mathrm{TM}}$ software version R2016a. Data matrix containing the peak areas of 39 ALEX samples was generated by PCA and later, the extracted data was represented by a set of new variables known as principal components (PCs).

\subsubsection{Scree Plot}

The first plot to analyse was scree plot presented in Figure 2. The scree plot displays the percentage of eigenvalue that represents the variance explained in each principal component. Martinez et al. (2017) describe the scree plot as the graphical way of determining the number of PCs to retain and it is suggested to keep PCs with the size of variances greater than $70 \%$. In contrary, Kumar et al. (2017) stated that at least $80 \%$ of the data set is required in order to ensure complete information of the data set without overfitting the model.

Figure 2(a) displays the scree plot generated based on the chemical profiles of the overall bioactive compounds constituted of 555 compounds (dataset A). The plot describes that $81 \%$ of the data were captured for dataset A. Meanwhile Figure 2(b) shows the scree plot generated based on the chemical profiles of bioactive compounds with mass spectral matching of more than 50\% (Qual > 50) with NIST 2008 mass spectral library constituted of 45 compounds (dataset B). The plot describes that $90 \%$ of the data was captured for dataset B. The smaller percentage of data captured for dataset A might be explained due to the large variability and inconsistency of the relative composition (\%) of the compounds identified across 39 samples of ALEX as compared to dataset $\mathrm{B}$. Therefore, the principal component generated based on the metabolite profile of dataset $\mathrm{B}$ which had more sufficient data been further analysed and discussed.

Based on Figure 2(b), 90\% of the data extracted from the metabolite profile of dataset B that stayed intact were represented by ten principal components (PC). Principal component is referred as the set of new variables obtained from the linear combinations of old variables (Kumar, 2017). Each PC denoted a number of variables that correlate with each other but are uncorrelated with the other variables in other PCs. The scree plot identified ten PCs which were arranged in decreasing order of variance. The first principal component, PC1 explained the maximum percentage of variance (the variability which identified the most important gradient in the data) of $18.90 \%$ followed by PC2 explained the second highest variation of $13.35 \%$ from the unexplained variance of the dataset and so forth. Accordingly, PC1 and PC2 were able to account for only $32.25 \%$ of the total variability.

\subsubsection{Score Plot}

Score and loading plots were generated based on dataset $\mathrm{B}$ which has captured more data as compared to the dataset A. In the present study, supposedly there should be 39 points appeared in the score plot representing the observation of 39 (13 x triplicates) ALEX samples. However, two samples (sample 2 from Run 1 and sample 4 from Run 2) were removed since all the bioactive compounds identified in these samples did not reach the similarity spectral matching of $50 \%$. Therefore, the removal of two samples from dataset B explained the presence of only 37 points in the score and loading plots. There were nine groups of ALEX extracted at different Soxhlet extraction time and ratio which can be referred in Table 4 .

The position of each point of samples in the score plot described the correlation between the samples and PCs. The points which appeared on the positive side of both $\mathrm{X}$ and $\mathrm{Y}$ axes implied that the samples were positively correlated with the PC while points which appeared on the negative side of $\mathrm{X}$ and $\mathrm{Y}$ axes implied that the samples were negatively correlated with the PC. Points at zero axis imply that the sample had no correlation with the PC. Accordingly, the distance of a sample to another sample indicates the similarities or differences of characteristics possessed by the samples. The close distance between the samples showed that the samples were highly similar and comparable. In this case, the separation of the ALEX samples which was based on the extraction time and solid to solvent ratio of Soxhlet process can be observed in the score plot (Figure 3 ). The score plot illustrates the separation and proximity of the extracts in accordance to the extraction time of 12 , 15 and $18 \mathrm{hrs}$ and solid to solvent ratio of 1:50, 1:60 and $1: 70$ representing 300,360 and $420 \mathrm{~mL}$ of absolute ethanol used to extract $6 \mathrm{~g}$ of $A$. malaccensis leaf. Samples were clustered mainly according to their biological triplicates.

It can be observed that PC1 in Figure 3 (a) and (b) 
(A)

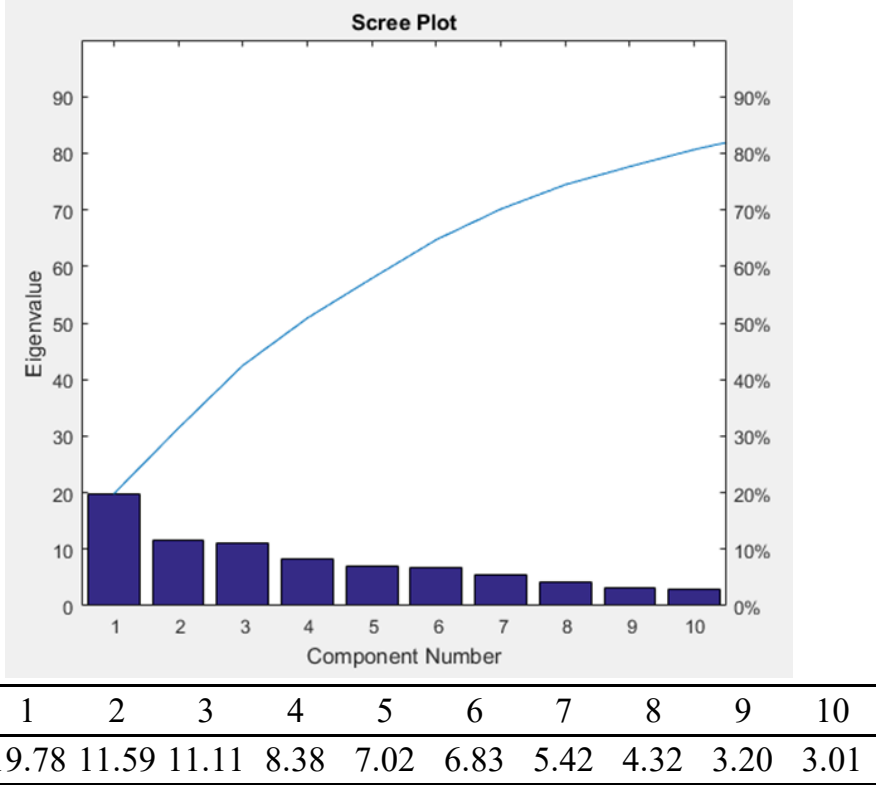

\begin{tabular}{ccccccccccc}
\hline X-axis & 1 & 2 & 3 & 4 & 5 & 6 & 7 & 8 & 9 & 10 \\
\hline Y-axis & 19.78 & 11.59 & 11.11 & 8.38 & 7.02 & 6.83 & 5.42 & 4.32 & 3.20 & 3.01
\end{tabular}

(B)

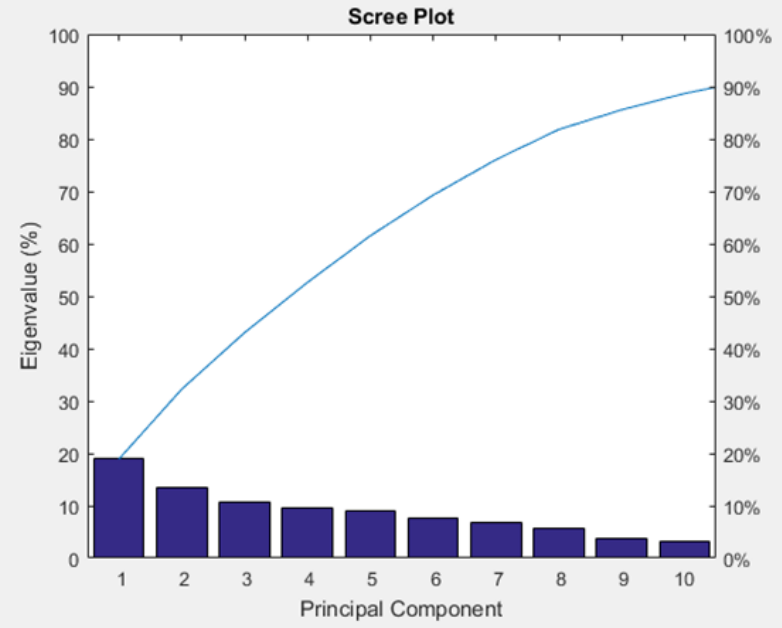

\begin{tabular}{lcccccccccc}
\hline X-axis & 1 & 2 & 3 & 4 & 5 & 6 & 7 & 8 & 9 & 10 \\
\hline Y-axis & 18.90 & 13.35 & 10.79 & 9.58 & 8.90 & 7.76 & 6.78 & 5.74 & 3.77 & 3.10 \\
\hline
\end{tabular}

Figure 2. Scree plot identifying ten principal components (PCs) representing the cumulative percentage of variance in the chemical profiles of (a) the overall bioactive compounds constituted 555 compounds (dataset A) and (b) the bioactive compounds constituted of 45 compounds with mass spectral matching of more than 50\% (Qual > 50) with NIST 2008 mass spectral library (dataset B)

Table 4. The samples of ALEX in accordance to the Soxhlet extraction times (12,15 and 18 hrs) and solid to solvent ratio (1:50, $1: 60$ and $1: 70 \mathrm{~g} / \mathrm{mL}$ )

\begin{tabular}{|c|c|c|c|c|}
\hline \multirow{2}{*}{ No. } & \multicolumn{2}{|c|}{ Soxhlet parameters } & \multirow{2}{*}{ Experimental run(s) } & \multirow{2}{*}{ ALEX samples } \\
\hline & Extraction time (h) & Solid to solvent ratio $(\mathrm{g} / \mathrm{mL})$ & & \\
\hline & & & 1 & 1,3 \\
\hline & & & 2 & 5,6 \\
\hline \multirow[t]{3}{*}{1} & 15 & $1: 60$ & 3 & $7,8,9$ \\
\hline & & & 4 & $10,11,12$ \\
\hline & & & 10 & $28,29,30$ \\
\hline 2 & 18 & $1: 70$ & 5 & $13,14,15$ \\
\hline 3 & 15 & $1: 70$ & 6 & $16,17,18$ \\
\hline 4 & 12 & $1: 50$ & 7 & $19,20,21$ \\
\hline 5 & 18 & $1: 60$ & 8 & $22,23,24$ \\
\hline 6 & 12 & $1: 60$ & 9 & $25,26,27$ \\
\hline 7 & 18 & $1: 50$ & 11 & $31,32,33$ \\
\hline 8 & 12 & $1: 70$ & 12 & $34,35,36$ \\
\hline \multirow[t]{2}{*}{9} & 15 & $1: 50$ & 13 & $37,38,39$ \\
\hline & & & al of ALEX samples & 37 \\
\hline
\end{tabular}

*Note: Sample 2 from Run 1 and sample 4 from Run 2 were removed since all the bioactive compounds identified in these samples did not reach the similarity spectral matching of $50 \%$. 
able to divide a majority of ALEX samples extracted for 15 (ALEX-15) and 18 (ALEX-18) hours on the negative side while for 12 (ALEX-12) hours on positive side of the component. Moreover, most of the samples of ALEX -15 and ALEX-18 were clustered in negative quadrant implying that the samples were negatively correlated with both PC1 and PC2. In contrary, most of the samples of ALEX-12 $(19,20,21,26)$ were positively correlated with PC1 but negatively correlated with PC2. Similarly, PC3 is also able to distinguish ALEX-15 and ALEX-18 on negative side while ALEX-12 on positive side of PC3. However, most of the samples were highly

(A)

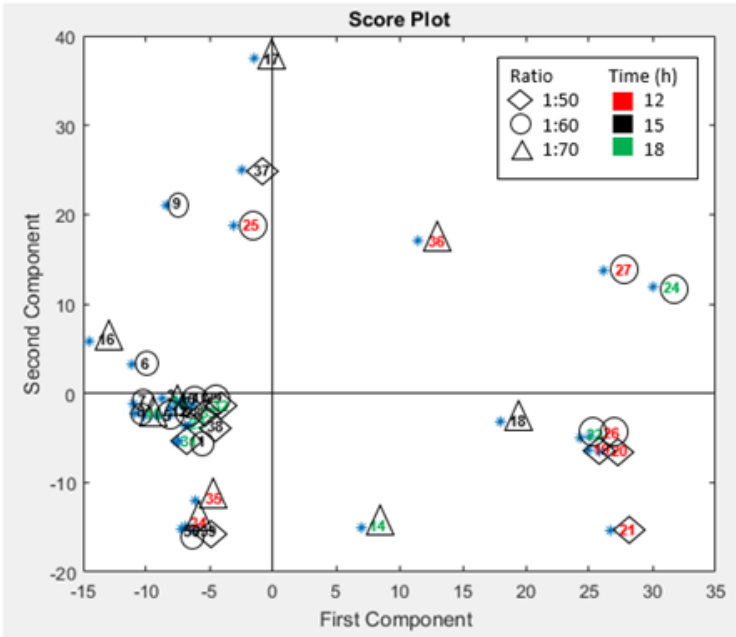

(B)

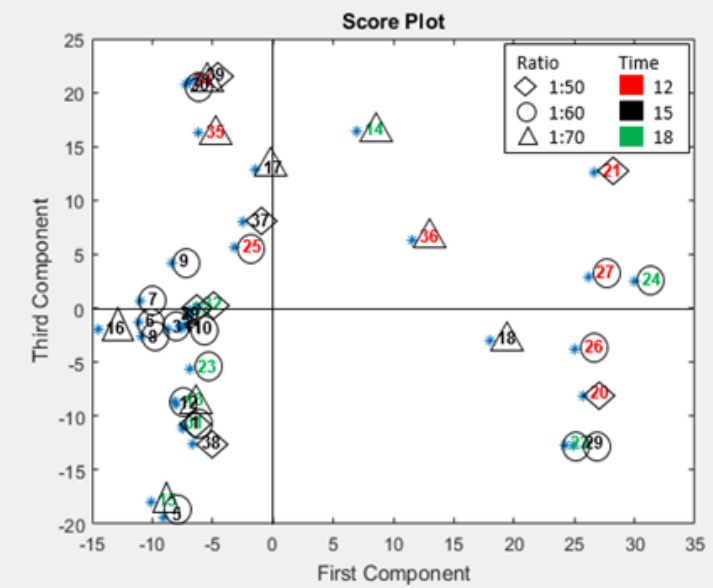

(C)

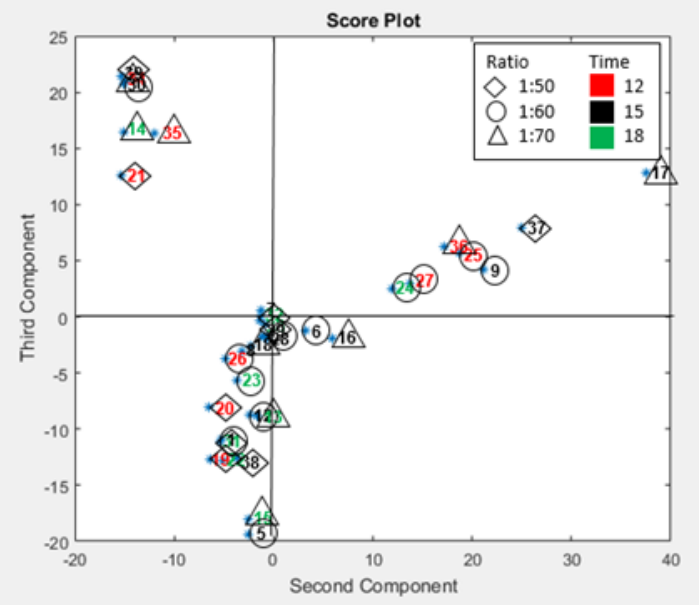

Figure 3. Score plots of (a) PC1 vs PC2, (b) PC1 vs PC3 and (c) PC2 vs PC3; describing the correlation of ALEX samples based on the Soxhlet extraction time and solid to solvent ratio with the principal components. correlated with PC1 as compared to PC3. Thus, it can be assumed that PC1 is represented by Soxhlet extraction time.

On the other hand, the separation of the ALEX samples associated with solid to solvent ratio can be observed in Figure 3 (b) PC1 against PC3 and (c) PC2 against PC3. In the score plot of PC1 against PC3, most of the samples extracted with ratio 1:70 (ALEX-70) were separated on the positive side of PC3, while the majority of 1:50 (ALEX-50) and 1:60 (ALEX-60) samples were clustered on the negative side of PC3. It can be spotted that most of the samples were clustered on the bottom left quadrant of the plot implying that the samples were negatively correlated with both PCs. Conversely, in the score plot of PC2 against PC3, majority of the samples were zero correlated with PC2 and PC3 was able to separate most of the ALEX-70 samples on positive side while ALEX-50 and ALEX-60 on negative side. Thus, it can be assumed that PC3 is represented by solid to solvent ratio. Nonetheless, the insignificant separation of the samples based on the solid to solvent ratio might be explained due to the small difference between the ratios. In particular, the difference of $60 \mathrm{~mL}$ of ethanol might not affect the metabolite profile of the extracts.

\subsubsection{Loading Plot}

Loading plot describes the important relationship of a specific variable to the component and samples. This plot provides the visualization of the specific variables (compounds) that were highly correlated with PCs for the particular sample types which responsible for the separation of sample clusters (Cordella, 2012; Kumar, 2017). The concept of score plot and loading plot are similar in which the variables that grouped together implying high similarity or correlation. In this case, the variables were represented by the individual detected bioactive compounds. The variables denoting specific compounds which highly correlated with the PCs are listed in Table 5.

Based on the loading plot in Figure 4, it can be seen that Variable 38 (V-38) representing Hexadecanoic acid, 2-hydroxy-1-(hydroxymethyl)ethyl ester had high correlation with PC1 and samples of ALEX-12 and ALEX-50 which justified the abundancy of this compound in samples 19 (33.65\%), 20 (33.95\%), 21 (34.57\%), 22 (32.85\%), 24 (34.89\%), 26 (33.573\%) and 27 (30.72\%). Likewise, V-8 representing Bicyclo[3.1.1] heptane, 2,6,6-trimethyl- was highly correlated with PC2 and samples of ALEX-15 in which this compound was found to be the major compound of samples 17 (44.40\%), $36(23.72 \%)$ and $37(31.69 \%)$ respectively. It can also be observed that V-9 representing Phytol, acetate was highly positively correlated with PC3 and 
(A)

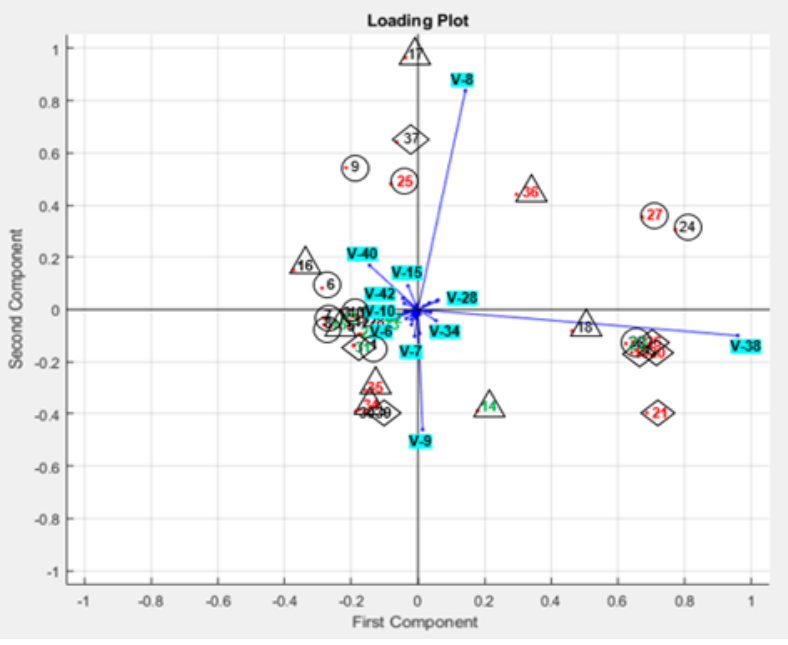

(B)

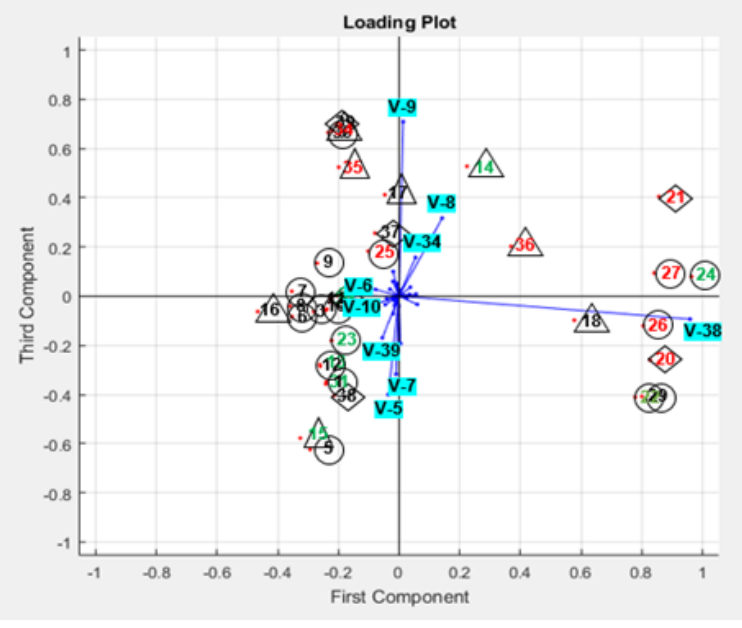

(C)

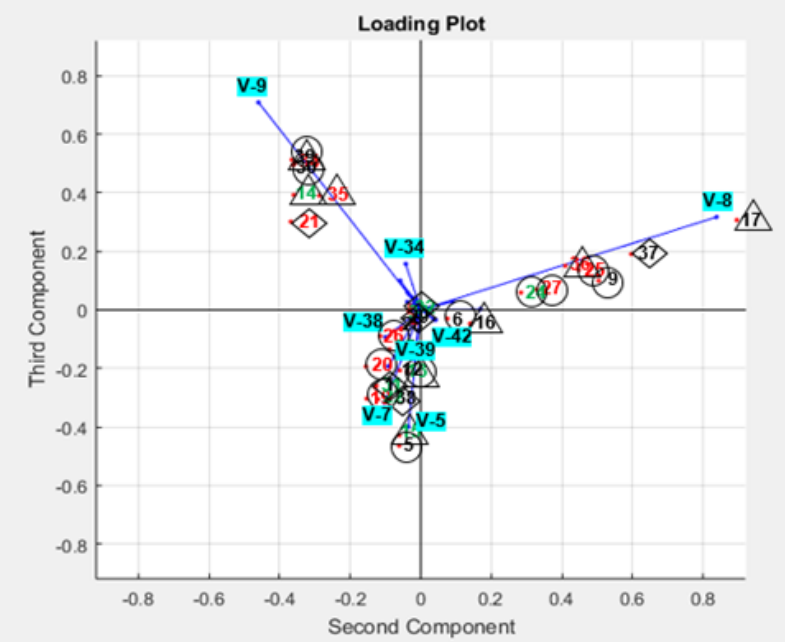

Figure 4. Loading plots of (a) PC1 vs PC2, (b) PC1 vs PC3 and (c) PC2 vs PC3; displaying the correlation between ALEX samples with specific variables represented by the individual bioactive compounds

samples of ALEX-70. Accordingly, V-5, V-7 and V-10 denoting 1,19-Eicosadiene, Bicyclo[3.1.1]heptane, 2,6,6trimethyl-, (1.alpha.,2.beta.,5.alpha.)- and 5-t-Butylcycloheptene having functional groups of alkane and alkene which are nonpolar were highly correlated with samples ALEX-15 and ALEX-60. Thus, it is suggested that the compounds with alkane and alkene groups can be obtained by using Soxhlet for 15 hours and the ratio of $1: 60$
Table 5. Variables represent by the individual bioactive compounds which highly correlated with the principal components.

\begin{tabular}{cl}
\hline Variable & \multicolumn{1}{c}{ Bioactive compounds } \\
\hline V-5 & 1,19-Eicosadiene \\
V-6 & 1,4-Eicosadiene \\
V-7 & $\begin{array}{l}\text { Bicyclo[3.1.1]heptane, 2,6,6-trimethyl-, } \\
\text { (1.alpha.,2.beta.,5.alpha.)- }\end{array}$ \\
V-8 & Bicyclo[3.1.1]heptane, 2,6,6-trimethyl- \\
V-9 & Phytol, acetate \\
V-10 & 5-t-Butyl-cycloheptene \\
V-15 & Butanoic acid, 3-methyl-, 3,7-dimethyl-6-octenyl \\
V-28 & 3,7,11,15-Tetramethyl-2-hexadecen-1-ol \\
V-34 & n-Hexadecanoic acid \\
V-38 & $\begin{array}{l}\text { Hexadecanoic acid, 2-hydroxy-1-(hydroxymethyl) } \\
\text { ethyl ester }\end{array}$ \\
V-39 & 16-Hexadecanoyl hydrazide \\
V-40 & Glycerol 1-palmitate \\
V-42 & Bis(2-ethylhexyl) phthalate \\
\hline
\end{tabular}

\section{Conclusion}

Metabolite profiling of ALEX in the present study was performed using gas chromatography-mass spectrometry (GCMS) analysis. A total of 39 extracts of $A$. malaccensis leaf based on 13 experimental (optimization) runs of RSM, CCD; gave a total of 555 bioactive compounds. There was only a total of 45 compounds with mass spectral matching of more than $50 \%$ (Qual > 50) with the registered compounds in NIST mass spectral library. n-Hexadecanoic acid and Hexadecanoic acid, 2-hydroxy-1-(hydroxymethyl)ethyl ester were found to be present in most of the ALEX samples. Interestingly, most of the detected compounds with hydrocarbon, terpenes and esters being the primary group, have diverse potential biological activities that can be used in developing functional foods and nutraceuticals. Consequently, the effects of Soxhlet extraction parameters on the bioactive compounds of ALEX samples were further studied through principal component analysis with the aid of MATLAB software. PCA showed that same parameters were able to cluster the samples together and separate samples extracted with different parameters based on the relative abundance of the particular compounds. It is notable that Soxhlet extraction time showed more significant effects on the yield and separation of the compounds as compared to the solid to solvent ratio. The identified parameter can be used to effectively obtain extracts with desired composition of compounds.

\section{Conflict of Interest}

The authors declare no conflict of interest. 


\section{Acknowledgments}

The research work was supported by the Research Initiative Grant Scheme (RIGS17-145-0720) received from International Islamic University Malaysia. The authors would like to thank the technicians and everyone who has, directly and indirectly, contributed in this present study.

\section{References}

Adam, A.Z., Lee, S.Y. and Mohamed, R. (2017). Pharmacological properties of agarwood tea derived from Aquilaria (Thymelaeaceae) leaves: An emerging contemporary herbal drink. Journal of Herbal Medicine, 10, 37-44. https://doi.org/10.1016/ j.hermed.2017.06.002

Adam, A.Z., Tajuddin, S.N., Sudmoon, R., Chaveerach, A., Abdullah, U.H., Mahat, M.N. and Mohamed, R. (2018). Chemical constituents and toxicity effects of leaves from several agarwood tree species (Aquilaria). Journal of Tropical Forest Science, 30 (3), 342-353. https://doi.org/10.26525/ jtfs2018.30.3.342353

Ahmad, A., Alkarkhi, A.F., Hena, S., Siddique, B.M. and Dur, K.W. (2010). Optimization of Soxhlet extraction of Herba Leonuri using factorial design of experiment. International Journal of Chemistry, 2 (1), 198. https://doi.org/10.5539/ijc.v2n1p198

Akter, S., Islam, M.T., Zulkefeli, M. and Khan, S.I. (2013). Agarwood production-A multidisciplinary field to be explored in Bangladesh. International Journal of Pharmaceutical and Life Sciences, 2(1), 22-32. https://doi.org/10.3329/ijpls.v2i1.15132

Ali, N.A.M., Ismail, N. and Taib, M.N. (2012). Analysis of agarwood oil (Aquilaria malaccensis) based on GC-MS data. 2012 IEEE 8th International Colloquium on Signal Processing and its Applications, p. 470-473. Malacca, Malaysia: IEEE Control System Society Chapter Malaysia. https:// doi.org/10.1109/CSPA.2012.6194771

Aparna, V., Dileep, K.V., Mandal, P.K., Karthe, P., Sadasivan, C. and Haridas, M. (2012). Antiinflammatory property of n-hexadecanoic acid: structural evidence and kinetic assessment. Chemical Biology and Drug Design, 80(3), 434-439. https:// doi.org/10.1111/j.1747-0285.2012.01418.x

Azwanida, N.N. (2015). A Review on the Extraction Methods Use in Medicinal Plants, Principle, Strength and Limitation. Medicinal and Aromatic Plants, 4 (3), 3-8.

Ballabio, D. (2015). A MATLAB Toolbox for principal component analysis and unsupervised exploration of data structure. Chemometrics and Intelligent
Laboratory Systems, 149(Part B), 1-9. https:// doi.org/10.1016/j.chemolab.2015.10.003

Casuga, F.P., Castillo, A.L. and Corpuz, M.J.A.T. (2016). GC-MS analysis of bioactive compounds present in different extracts of an endemic plant Broussonetia luzonica (Blanco) (Moraceae) leaves. Asian Pacific Journal of Tropical Biomedicine, 6(11), 957-961. https:// doi.org/10.1016/j.apjtb.2016.08.015

Ciarlini, J.J.S., Marangoni, A. and Bolzan, A. (2017). Selectivity of supercritical $\mathrm{CO}_{2}$ extraction and atmospheric pressure techniques for the major volatile compounds of Eugenia involucrata leaves from Southern Brazil. Food and Bioproducts Processing, 106, 9-34. https://doi.org/10.1016/ j.fbp.2017.08.008

Cordella, C.B. (2012). PCA: the basic building block of chemometrics. In Analytical Chemistry. InTechOpen (Online E-Book). Retrieved from InTech website: https://www.intechopen.com/books/analyticalchemistry/pca-the-basic-building-block-ofchemometrics

Eissa, M., Hashim, Y.Z.H-Y. and Zainurin, N.A.A. (2018). Aquilaria malaccensis leaf as an alternative source of anti-inflammatory compounds. International Journal on Advanced Science, Engineering and Information Technology, 8, 1625-1632. https://doi.org/10.18517/ ijaseit.8.4-2.7054

Hashim, M.N. and Zuhaidi, Y.A. (2011). Botany and ecology of Karas (Aquilaria malaccensis). Tapping the wealth from Karas (Aquilaria malaccensis) tree.

Hashim, Y.Z.H-Y., Ismail, N.I. and Abbas, P. (2014). Analysis of chemical compounds of agarwood oil from different species by gas chromatography mass spectrometry (GCMS). IIUM Engineering Journal, 15(1), 55-60. https://doi.org/10.31436/ iiumej.v15i1.469

Hashim, Y.Z.H-Y., Kerr, P.G., Abbas, P. and Mohd Salleh, H. (2016). Aquilaria spp. (agarwood) as source of health beneficial compounds: A review of traditional use, phytochemistry and pharmacology. Journal of Ethnopharmacology, 189, 331-360. https://doi.org/10.1016/j.jep.2016.06.055

He, L., Gielen, G., Bolan, N.S., Zhang, X., Qin, H., Huang, H. and Wang, H. (2015). Contamination and remediation of phthalic acid esters in agricultural soils in China: a review. Agronomy for Sustainable Development, 35(2), 519-534. https:// doi.org/10.1007/s13593-014-0270-1

Ibrahim, A. (2016). Comparative Analysis of in-vitro bioactivities and phenolic content of leaf extracts 
from six species of Aquilaria. Malaysia: Universiti Sains Malaysia, PhD. Dissertation.

Jok, V.A., Che Radzi, N. and Ku Hamid, K.H. (2015). A review: Pharmacological properties of Aquilaria spp. Advanced Materials Research, 1113, 193-197. https://doi.org/10.4028/www.scientific.net/ AMR.1113.193

Jolliffe, I.T. and Cadima, J. (2016). Principal component analysis: A review and recent developments. Philosophical Transactions of the Royal Society A, 374(2065), 20150202. https:// doi.org/10.1098/rsta.2015.0202

Jong, P.L., Tsan, P. and Mohamed, R. (2014). Gas chromatography-mass spectrometry analysis of agarwood extracts from mature and juvenile Aquilaria malaccensis. International Journal of Agriculture and Biology, 16(3), 644-648.

Kakino, M., Tazawa, S., Maruyama, H., Tsuruma, K., Araki, Y., Shimazawa, M. and Hara, H. (2010). Laxative Effects of agarwood on low-fiber dietinduced constipation in rats. BMC complementary and Alternative Medicine, 10, 68. https:// doi.org/10.1186/1472-6882-10-68

Khalil, A.S., Rahim, A.A., Taha, K.K. and Abdallah, K.B. (2013). Characterization of methanolic extracts of agarwood leaves. Journal of Applied and Industrial Sciences, 1(3), 78-88.

Kumar, K. (2017). Principal component analysis: Most favourite tool in chemometrics. Resonance, 22(8), 747-759. https://doi.org/10.1007/s12045-017-05239

Lee, N.Y., Yunus, M.A.C., Idham, Z., Ruslan, M.S.H., Aziz, A.H.A. and Irwansyah, N. (2016). Extraction and identification of bioactive compounds from agarwood leaves. IOP Conference Series: Materials Science and Engineering, 162, 012028. https://doi.org/10.1088/1757-899X/162/1/012028

Maharani, R., Fernandes, A., Turjaman, M., Lukmandaru, G. and Kuspradini, H. (2016). The characterization of phytochemical and GC-MS analysis on Borneo Agarwood (Aquilaria malaccensis Lamk) leaves and its utilization as an anti-browning in apple juice. International Journal of Pharmacognosy and Phytochemical Research, 8 (10), 1576-1582.

Martinez, W.L., Martinez, A.R. and Solka, J. (2017). Exploratory data analysis with MATLAB. United Kingdom: Chapman and Hall/CRC.

Maruthupandian, A. and Mohan, V.R. (2011). GC-MS analysis of ethanol extract of Wattakaka volubilis (lf) stapf. leaf. International Journal of Phytomedicine, 3(1), 59-62.
Mushtaq, S., Abbasi, B.H., Uzair, B. and Abbasi, R. (2018). Natural products as reservoirs of novel therapeutic agents. EXCLI journal, 17, 420-451. https://doi.org/ 10.17179/excli2018-1174.

Rostagno, M.A. and Prado, J.M. (Eds.). (2013). Natural product extraction: Principles and applications. United Kingdom: Royal Society of Chemistry. https://doi.org/10.1039/9781849737579

Sen, S., Talukdar, N. C. and Khan, M. (2015). A simple metabolite profiling approach reveals critical biomolecular linkages in fragrant agarwood oil production from Aquilaria malaccensis-A traditional agro-based industry in Northeast India. Current Science, 108, 63-71.

Sermakkani, M. and Thangapandian, V. (2012). GC-MS analysis of Cassia italica leaf methanol extract. Asian Journal of Pharmaceutical and Clinical Research, 5(2), 90-94.

Suhaila, A.S., Norihan, M.S., Norwati, M., Azah, M.N., Mahani, M.C., Parameswari, N., Kodi, I.K., Mailina, J., Azrina, A., Hasnida, H.N. and Haliza, I. (2015). Aquilaria malaccensis polyploids as improved planting materials. Journal of Tropical Forest Science, 27(3), 376-387.

U.S. Department of Agriculture, Agricultural Research Service. (2019). Dr. Duke's Phytochemical and Ethnobotanical Databases. Retrieved on September 12, 2018 from Website: https:// phytochem.nal.usda.gov/phytochem/search/list

Wang, S., Yu, Z., Wang, C., Wu, C., Guo, P. and Wei, J. (2018). Chemical constituents and pharmacological activity of agarwood and Aquilaria plants. Molecules, 23(2), 342. https:// doi.org/10.3390/molecules23020342

Zainurin, N.A., Hashim, Y.Z.H-Y., Azmin, N.F.M. and Abbas, P. (2018). Agarwood Leaf Essential Oil Characterization and Effects on MCF-7 Breast Cancer Cells. International Journal on Advanced Science, Engineering and Information Technology, 8(4-2), 1604-1609. https:// doi.org/10.18517/ijaseit.8.4-2.7034

Zainurin, N.A. (2019). Extraction and GCMS-Based Profiling of Bioactive Compounds from Agarwood (Aquilaria malaccensis) Leaf. Malaysia: International Islamic University Malaysia, MSc. Thesis. 